\title{
Morpho-Structural and Mechanical Characterization of Alloyed Steel
}

\author{
ECATERINA MAGDALENA MODAN², ADRIANA GABRIELA PLAIASU2*, MARIA MAGDALENA DICU², MARIAN CATALIN DUCU1*, \\ SORIN GEORGIAN MOGA', DUMITRU CHIRLESAN²* \\ 'University of Pitesti, CRC\&D-Auto, 11 Doaga, Pitesti, Romania \\ 2University of Pitesti, 1 Targu din Vale, 110040, Pitesti, Romania

\begin{abstract}
Our research focuses on the microstructure and mechanical properties of S6-5-2 speed steel. Studying austenite transformation in martensite and chemical composition changes of high speed steel, under heating conditions for austenitisation and cooling in oil bath, both performed under sub-atmospheric pressure (in rarefied atmospheres) is experimentally determined. The fields were these alloys can be preferred are: the electrical machines for avionics, the magnetic circuits of ultra-rapid relays and of other devices working in $D C$ fields, the measure transformers and other transformers supplied on industrial frequency. To analyze microstructure's modifications a combination of optical, scanning and electron microscopy was used. The mechanical properties were measured by hardness tests.
\end{abstract}

Keywords: heat treatment of quenching, austenite, martensite, hardness, microstructure

Thermal quenching treatment aims to harden steels with a carbon content of more than $0.30 \%$ by mass. This treatment, which applies to finished products, is intended to provide high hardness and mechanical strength to parts subjected to surface friction (gears, cranks, cutting tools, etc.).

The treatment consists in heating the steel at temperatures within a critical range above Ac3 (for hypoeutectoid steels) or between Ac1 and Ac3 (for hypereutectoid steels), and cooling it at a speed higher than critical speed.

In the case of high-alloy steels (such as tool steels), some of the alloying compound concentration is dissolved in the basic solid solution (their solubility increases with increasing temperature), the remainder being in the microstructure as compounds of these elements with carbon (carbides). It is the case of chromium, tungsten, vanadium etc.

The steels containing alloying elements have a simple equilibrium diagram and are malleable, allowing to obtain easily samples of reduced thicknesses that can be annealed at any temperature. The useful application can be: the electrical machines for avionics, the magnetic circuits of ultra-rapid relays and of other devices working in DC fields, the measure transformers, other transformers supplied on industrial frequency and many important applications in high frequency [1-2].

It is recognized that the metallurgical phase is a more important parameter for the reflectance behavior than the detailed content of the alloying elements. The soft iron still remains the best material for DC electromagnets, because its high saturation flux density allows obtaining an important magnetic flux homogeneously distributed. Also The Fe-Ni alloys, often called permalloys, are the most versatile from all the known soft magnetic materials [34].

In the hardening structure of these steels the carbides are maintained, as only the ferrite matrix suffers martensitic transformation. In addition, carbides are very hard compounds. Their presence in the rapidly hardened steel structure contributes to the high hardness value required for the product to have mechanical characteristics corresponding to the functional role of the product, which requires very good resistance to contact rubbing [5-7].

Every thermal treatment clues to certain physical and mechanical properties of treated samples, linked to the modified material structure.

\section{Experimental part \\ Materials}

The metallic material used was obtained from a fast 6 5-2 steel ingot, about $250 \mathrm{~kg}$, which was delivered in the form of rolled and peeled bars in an annealed condition with a diameter of $30 \mathrm{~mm}$.

The chemical composition of the material used was determined by quantitative chemical analysis (spectral method), according to standard Table 1.

In order to establish a proper quenching technology in rarefied atmospheres it was necessary to determine the following: the critical points of the material used; austenitic temperature; the isothermal maintenance time at this temperature. The critical temperatures of the used $S 6-5-2$ steel have the following values: $\mathrm{Acl}=860^{\circ} \mathrm{C} ; \mathrm{Ar} 1=760^{\circ} \mathrm{C}$; Accm $=980^{\circ} \mathrm{C} ; \mathrm{Arcm}=840^{\circ} \mathrm{C}$. The installation used did notallow the critical points Msand Mf to be determined. In this experimental research, the rarefied atmosphere installation was used only to perform thermal quenching treatment. The recovery was carried out in an exothermic controlled nitrogen atmosphere oven. In order to determine the optimal austenitic temperature, several heating regimes were followed, followed by hot oil cooling, from different heating temperatures $\left(1180^{\circ} \mathrm{C}, 1200^{\circ} \mathrm{C}\right.$ and $1220^{\circ} \mathrm{C}$ ), the isothermal maintenance times at the maximum temperature of each heating cycle being listed in Table 2. In all cases, isothermal heating was maintained to equalize the temperature in the load mass at $600^{\circ} \mathrm{C}$ and

\begin{tabular}{|c|c|c|c|c|c|c|c|c|}
\hline $\begin{array}{c}\text { The steel } \\
\text { brand }\end{array}$ & \multicolumn{7}{|c|}{ Chemical composition, \% } \\
\cline { 2 - 7 } & $\mathrm{C}$ & Mn & $\mathrm{Si}$ & $\mathrm{Cr}$ & $\mathrm{Mo}$ & $\mathrm{W}$ & $\mathrm{V}$ & $\begin{array}{c}\text { Other } \\
\text { elements }\end{array}$ \\
\hline $\mathrm{S} 6-5-2$ & 0.75 & 0.30 & 0.25 & 4.05 & 4.82 & 6.37 & 1.70 & $\begin{array}{c}\text { traces of } \\
\text { Co }\end{array}$ \\
& & & & & & & & $\begin{array}{c}\text { Table 1 } \\
\text { THE CHEMICAL COMPOSITION OF THE MATERIAL }\end{array}$ \\
\end{tabular}

*email: gabriela.plaiasu@upit.ro, catalin.ducu@upit.ro, dumitru.chirlesan@upit.ro 
$850^{\circ} \mathrm{C}$ for 15 minutes each, given that at these temperatures the transmission of heat from the heating source to the metallic load is quite difficult, these steels having a low thermal conductivity because of the non-homogeneous microstructure (solid solution and carbides).

Table 2

EXPERIMENTAL CONDITIONS

\begin{tabular}{|c|c|c|c|}
\hline \multirow{2}{*}{$\begin{array}{c}\text { Symbol } \\
\text { lot }\end{array}$} & \multirow{2}{*}{$\begin{array}{c}\text { Austenitizing } \\
\text { temperature, }\end{array}{ }^{\circ} \mathrm{C}$} & \multicolumn{2}{|c|}{ Isothermal maintenance time } \\
\cline { 3 - 4 } & & $\mathrm{s} / \mathrm{mm}$ & $\mathrm{min}$ \\
\hline $5 \mathrm{~V} 1$ & 1180 & 45 & 15 \\
\hline $5 \mathrm{~V} 2$ & 1200 & 45 & 15 \\
\hline $5 \mathrm{~V} 3$ & 1220 & 45 & 15 \\
\hline
\end{tabular}

\section{Characterizations}

Metallographic analysis was performed on an Olympus Basic 51M optical microscope to highlight the structure obtained from heat treatment and to measure austenite grains. For this purpose, the samples were prepared metallographically on a specialized machine (sanding followed by polishing on sandpaper and felt) and attacked with chemical reagent (nital 3\%); the metallographic study was performed in reflected light at magnification of 500X; measurement of austenite grains was done with the Olympus Stream application, Image Analysis Software.

Quantitative phase analysis was performed using the Scanning Electron Microscope (SEM, Hitachi SU5000). The SEM microscope has coupled an EDS detector (energydispersive detector), which allows elemental quantitative analysis.

Vickers hardness test (HV), performed according to SR EN ISO 6507 Metallic materials: Vickers duration test Part 1: test method, before the measurements were made, the appliance was checked in accordance with SR EN ISO 6507 Part 2 - Verification and calibration of testing machineries and SR EN ISO 6507 Part 3-Standard reference blocks. The hardness measurements were performed with a $5 \mathrm{~N}$ load (HV 0.5), using an Innovatest - Falcon 500.

\section{Results and discussions}

Following heating for austenitization, the fast-acting S5-2 steel microstructure was modified as follows: the ferrite turned into austenite and the carbides of the alloying elements remained unchanged. Thus, at maximum temperature, the microstructure consisted of austenite and carbides.

\section{Dimensions of austenite grains sample}

Depending on the maximum temperature of each sample batch, the microstructures presented austenite grains of different sizes, with the increase in the maximum temperature the size of the grains also increased. Measurement of these sizes was performed using the optical microscope application on a sample from each batch, taking into account three randomly chosen fields. Five measurements were made in each field so that it is possible to estimate as accurately as possible the influence of temperature on the size of the austenite grains.

Fig. 1 shows the microstructures used to determine the grain size for the 5V1, 5V2 and 5V3 samples.

For each sample were performed five measurements. The mean value of austenite grains for the $5 \mathrm{~V} 1$ sample (austenitizing temperature: $1180^{\circ} \mathrm{C}$ ) is $15.70 \mu \mathrm{m}$, for the 5V2 sample (austenitizing temperature: $1200^{\circ} \mathrm{C}$ ) is 19.86 $\mu \mathrm{m}$ and for the $5 \mathrm{~V} 3$ sample (austenitizing temperature: $1220^{\circ} \mathrm{C}$ ) is $13.32 \mu \mathrm{m}$.

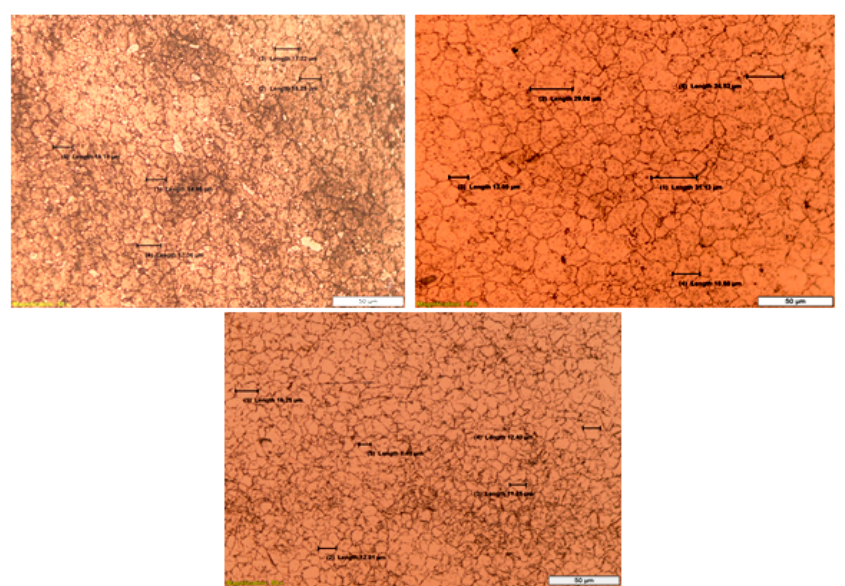

Fig.1. Grain size determination for sample 5V1, 5V2, 5V3

The measured values were used to calculate an average value for each field after the extreme values were removed. The average values of austenite grains are around 14.5 $\mu \mathrm{m}$. Such microstructures result in the formation of a nonuniform quenching martensite with martensitic rough areas and a larger proportion of residual austenite, which adversely affects the mechanical properties of the material, in this case its wear resistance contact.

Figure 2 and 3 shows the images of the quenching microstructures of the samples in the $5 \mathrm{~V} 1$ and $5 \mathrm{~V} 3$ lots. If in the first case a homogeneous martensitic structure is observed, in the second case it is observed that martensitic areas alternate with areas rich in residual austenite (remaining unformatted).

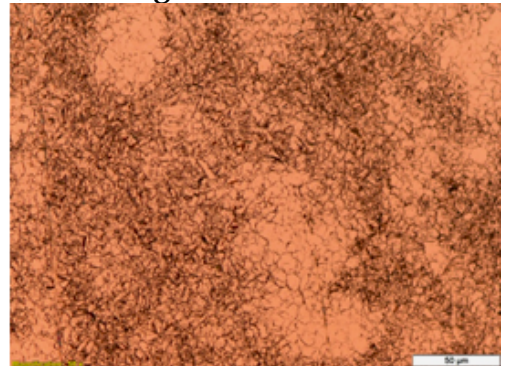

Fig.2. The microstructure of a sample from the 5V1 lot after martensitic hardening at a temperature of $1180^{\circ} \mathrm{C}$

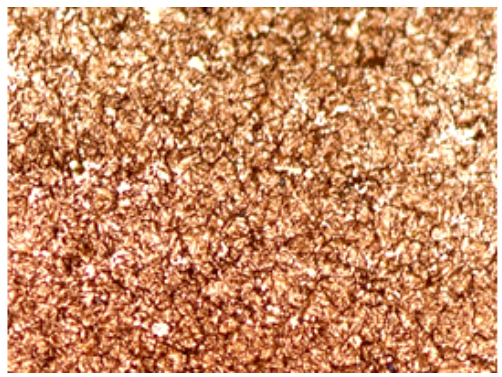

Fig.3. The microstructure of a sample from the $5 \mathrm{~V} 3$ lot after martensitic hardening at a temperature of $1220^{\circ} \mathrm{C}$

These results, obtained from the measurement of the austenite grains, which suffered at the martensitic transformation, lead us to consider the austenitizing temperature of $1180^{\circ} \mathrm{C}$ as the optimal temperature for thermal quenching, the temperature at which the martensitic transformation takes place in the most good conditions. This is the case for the $5 \mathrm{~V} 1$ sample batch.

The hardness measurements confirm that the 5V1 lot was austenitized at the optimum temperature because the highest values were recorded in this group (Table 3 ).

\section{Carbon particle size}

The carbide particles are located at the limits of the austenite grains (Fig. 4).

During the austenitic heating, the carbons dissolve partially in the austenite, enriching the alloying element content. Their presence, however, has the effect of limiting the growth of austenite grains with increasing temperature. 
Table 3

AVERAGE HARDNESS VALUES (MEAN OF 5 VALUES PER SAMPLE)

\begin{tabular}{|c|c|c|}
\hline \multirow{2}{*}{ Sample code } & \multicolumn{2}{|c|}{ hardness (average values) } \\
\cline { 2 - 3 } & HV0.5 & HRC \\
\hline 5V1 & 688.4 & 59.6 \\
\hline 5V2 & 722.66 & 61.06 \\
\hline 5V3 & 612.57 & 55.95 \\
\hline
\end{tabular}
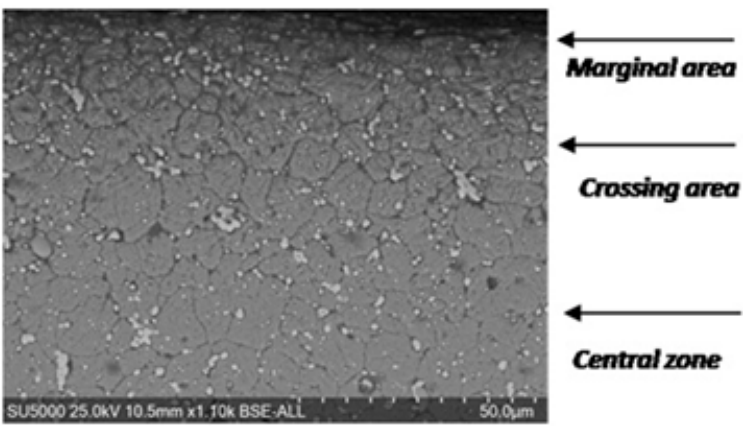

Fig.4. SEM microstructure in the 5V1 lot: austenite grains (dark color) and white particles (white)

As we have shown before, their action is sharply reduced when the austenitizing temperature exceeds a certain value, because very small particles completely dissolve in austenite.

Fig. 5 and 6 shows the micrographs SEM for the austenite grains and the carbide particles. Fig. 6a shows that the layer size is $6.33 \mu \mathrm{m}$, the transition layer is $10.9 \mu \mathrm{m}$, and the average size of the carbide particles is $3.07 \mu \mathrm{m}$. In the central area the average particle size of the carbide particles is $3.025 \mu \mathrm{m}$, fig. $6 \mathrm{~b}$.

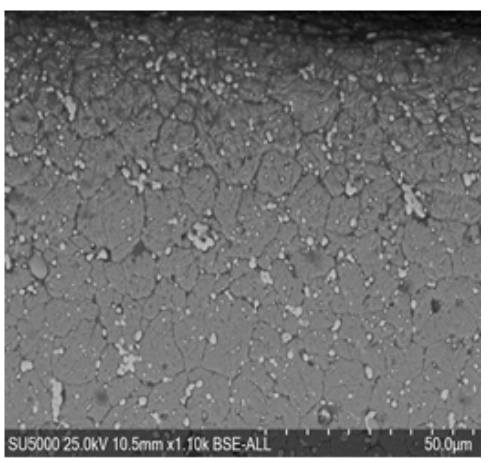

Fig.5. SEM micrograph of 5V1: austenite grains (dark color) and carbide particles (white)

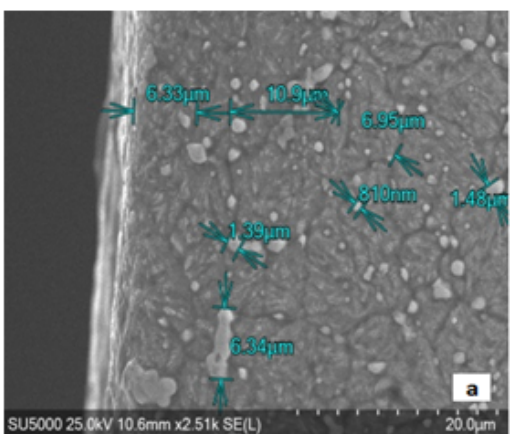

Fig.6. SEM micrographs of carbide particle: a. the layer size, the transition layer and the average size, b. the center of the

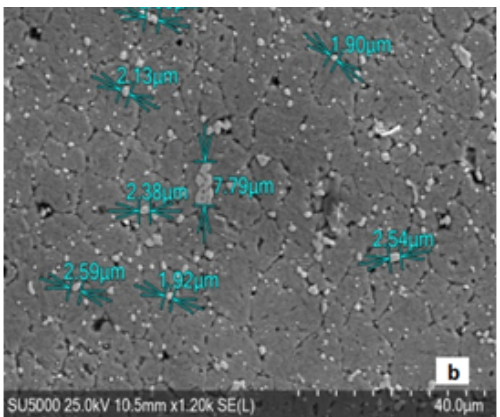
sample

Chemical composition of the metal matrix and carbides

The nature and chemical compositions of the metal matrix and carbide particles were determined by the EDS analysis method. Two sample areas of the 5V1 lot were analyzed. An overview of an analyzed area shows that the metal matrix is allied with the chemical elements existing in carbides (Fig. 7 and 8).

Spectral analyses were performed at four points: three of the spectra refer to the analysis of the carbons covered by the SEM images in Fig. 7. The fourth spectrum refers to the chemical composition of the metal matrix of the sample. Spectral analysis showed that the analyzed steel (S 6-5-2) has complex carbide structures, which contain the main alloying elements $(\mathrm{V}, \mathrm{Cr}, \mathrm{Mo}, \mathrm{W})$ in different concentrations.

Fig.7. EDS mapping of analyzed area
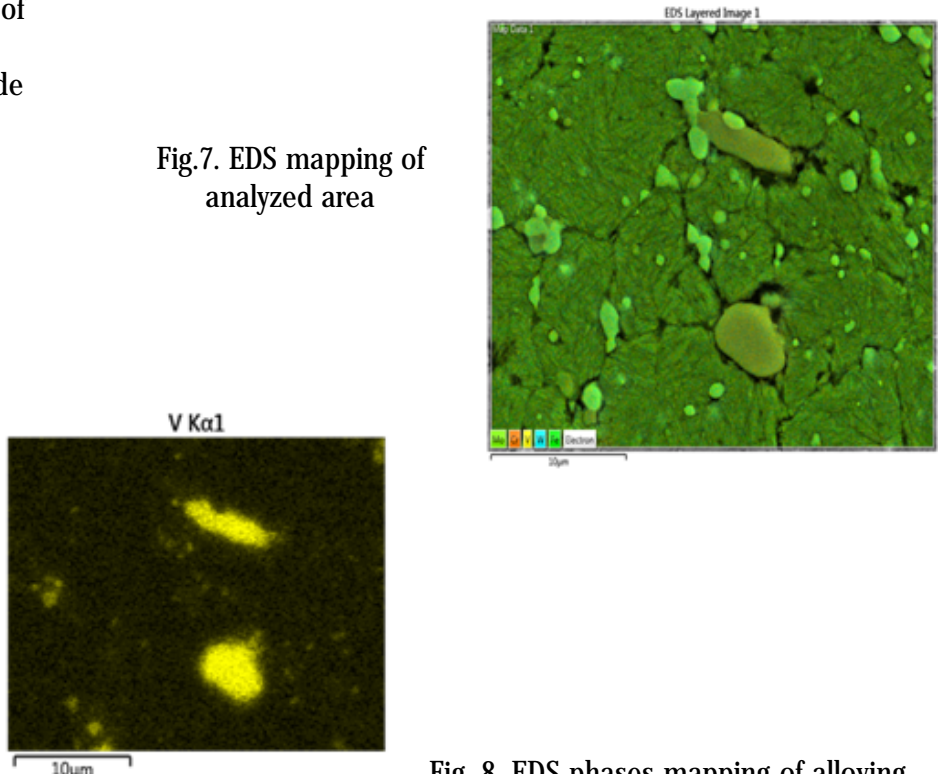

Fig. 8. EDS phases mapping of alloying

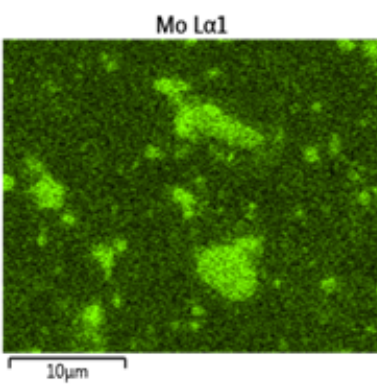

3849 elements in the matrix, chemical composition and carbide particles
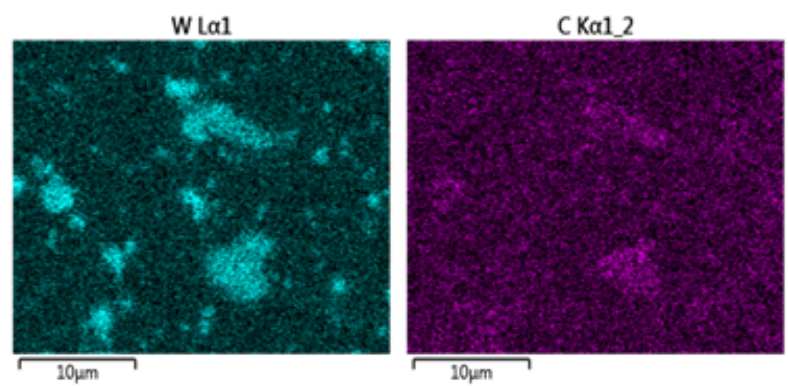

http://www.revistadechimie.ro

REV.CHIM.(Bucharest) $70 \bullet$ No. 11 2019 
These figures are presented the spectrum obtained at the points fixed on the SEM image in Fig.6, the concentrations of alloying elements in the carbide particles (Fig.9) and in the metal matrix (Fig.10).

Fig 9 refers to carbide in which the dominant element is vanadium (31.97\%), followed by tungsten $(18.56 \%)$ and molybdenum (11.90\%).

Fig.10 describes the chemical composition of the metal matrix, which contains, in addition to iron (80.35\%) and carbon (6.60\%), alloying elements present in carbides.

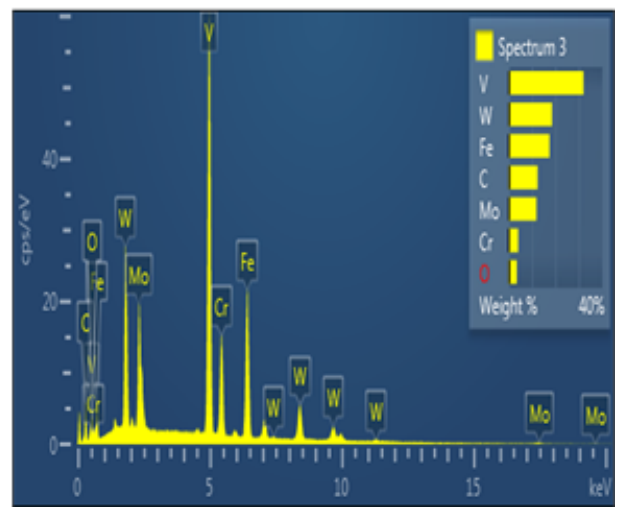

Fig.9. EDS spectrum of the chemical composition of the carbides

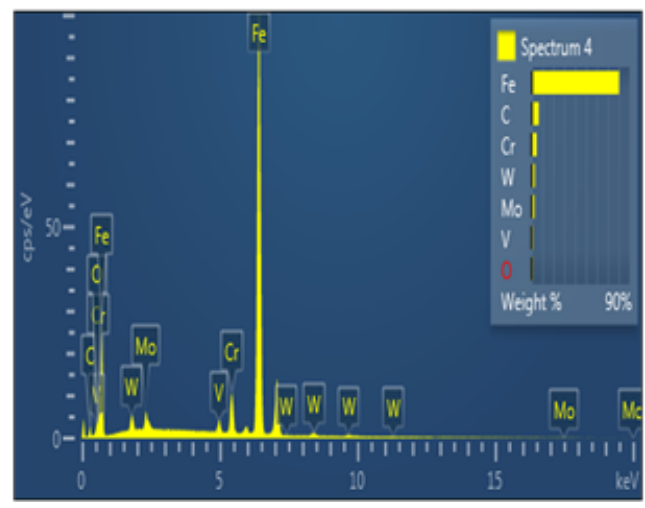

Fig.10. EDS spectrum of the chemical composition of the metallic matrix

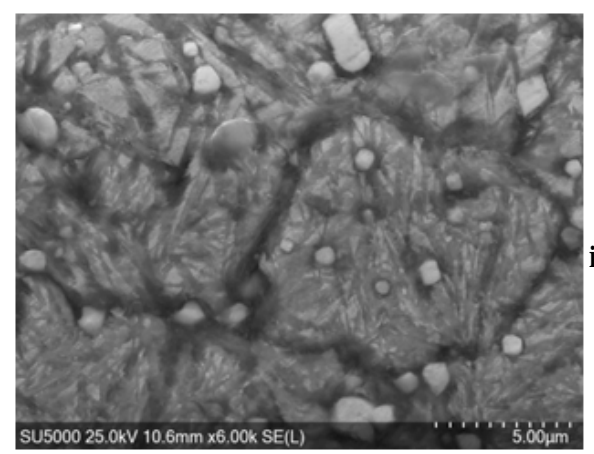

Fig.11. The SEM image of martensitic structure

\section{Martensitic transformation}

The martensitic transformation was carried out by cooling the samples in oil at austenitizing temperature (in the case of analyzed samples - batch 5V1 - the austenitizing temperature was $1180^{\circ} \mathrm{C}$ ). The fig. 11 shows that martensite has the typical needle pack structure and the carbide has the parallelepiped shape. For a complete transformation of austenite, the tempered samples were subjected to two returns, at $550^{\circ} \mathrm{C}$, with an isothermal maintenance of one hour.

\section{Conclusions}

The purpose of this paper was to study martensitic transformation in high alloyed steels using heat-treated vacuum samples. For these experimental investigations, a high grade of steel was used: S 6-5-2. The heat treatment cycle included oil cooling and two incomes.

The total number of samples was divided into three groups that were rated 5V1, 5V2 and 5V3. Each group of samples was austenitized to another temperature: $5 \mathrm{~V} 1$ at $1180^{\circ} \mathrm{C}, 5 \mathrm{~V} 2$ at $1200^{\circ} \mathrm{C}$ and $5 \mathrm{~V} 3$ at $1220^{\circ} \mathrm{C}$. Each intake was made at $550^{\circ} \mathrm{C}$. Structural changes were performed by optical microscopy and scanning electron microscopy (SEM).

The mechanical properties were determined by the Vickers hardness method. Carbide particles are detected at austenite grains limits. When heated to austenitization, the carbons dissolve partially in austenite and enrich the alloy content. Martensite crystals (needles) formed in austenite grains, next to carbide particles. Sample analysis indicated the influence of austenitizing temperature on sample microstructures (particle size and carbide particles, carbon content and alloying elements of metallic mass), which leads to the conclusion that the austenitizing temperature of $1180^{\circ} \mathrm{C}$ is the most suitable for thermal treatment for cooling. Even the hardness values confirmed this conclusion, the highest values being determined for the $5 \mathrm{~V} 1$ samples.

Every thermal treatment clues to certain physical and mechanical properties of treated samples linked to the modified material structure which leads to potential application in optoelectronic field.

The high speed steel shows high toughness and good cutting power owing, making it suitable for a wide variety of applications: for all metal-cutting tools for roughing or finishing, segments for circular saws, shaping tools, woodworking tools, cold-forming tools, as well as for cutting and precision cutting tools, plastics moulds with elevated wear resistance and screws.

\section{References}

1. MINCIUNA, M.G., VIZUREANU, P., ACHITEI, D.C., GHIBAN, B., SANDU, A.V., MARECI, D., BALAN, A., Rev. Chim.(Bucharest), 65, no. 10, 2014, p. 1138.

2. IORDACHE, D.M., NITU, E.L., PLAIASU, A.G., BOTILA, L.N., DUCU, M.C., PASARE, M.M., Rev. Chim.(Bucharest), 68, no. 8, 2017, p. 1811. 3. RUSANESCU, C.O., RUSANESCU, M., Rev. Chim. (Bucharest), 69, no. 9,2018, p. 2357

4. SHAABAN, E.R., ELSHAIKH, H.A., SORAYA, M.M., Optoelectron. Adv. Mat., 9, 2015, p. 587.

5. GRUMBACH M., extrait Techniques de I'Ingenieur, Methodes de caracterisation et d'analyse des metaux et alliages, Vieillissement des aciers, Ref : M235, 1, 1993, p. 49.

6. GIORGETTI, A., MONTI, C., TOGNARELLI, L., MASTROMATTEO, F., Results in Physics, 7, 2017, p. 1608.

7. YANGA, Y., YANA, M.F., ZHANGA, S.D., GUOA, J.H., JIANGA, S.S., LIB, D.Y., Surf. Coat. Technol, 96, 2018, p. 3333.

Manuscript received: 20.06 .2019 